\title{
Computer use in psychology instruction: A survey of individual and institutional characteristics
}

\author{
PETER A. HORNBY and MARGARET D. ANDERSON \\ State University of New York College, Plattsburgh, New York
}

\begin{abstract}
This paper reports the results of a national survey of psychology faculty regarding their instructional use of computers. The survey was designed to answer three general questions: (1) In what ways and to what extent are psychologists using computers in their instruction? (2) What individual characteristics differentiate among levels of users? (3) What institutional characteristics appear to promote or inhibit the instructional use of computers? The results reveal that, although there appears to be extensive use of computers to support instruction, there are both institutional and individual characteristics that differentiate among levels and types of use. Several factors are identified that could lead to increased instructional use of computers, but their impact will largely be determined by the characteristics of the individual and the institution.
\end{abstract}

Microcomputer laboratories are available on most college campuses, and software to support a broad range of psychology instruction is becoming readily available (Anderson \& Hornby, 1989; Stoloff \& Couch, 1992). Surveys (Anderson \& Hornby, 1990; Carpenter, 1986; Castellan, 1982; Couch \& Stoloff, 1989) have revealed an increasing use of microcomputers by psychologists to support their instruction. There is, however, considerable variation in the extent and manner in which computers are being used to support instruction. To account for this variation, a number of different hypotheses can be considered. Individuals who are not using computers may simply not be aware of the available technology. People may be aware of the technology, but may not know how to incorporate it into their teaching. It is equally possible that individuals are actively choosing not to use computers due to personal attitudes or beliefs about teaching. There might also be specific institutional factors that tend to promote or inhibit the use of computers in instruction. Any approach to stimulating or enhancing the use of computerized instruction will have to be based on an identification and understanding of the factors involved. Unfortunately, however, up-to-date data that can be used to inform decisions in this regard are not currently available.

Previous surveys do provide some historical data relevant to these issues. Castellan (1982), for example, found greater use of instructional computing in small departments than in large ones, as well as more use at smaller institutions. He also found the use of computers in instruction to be shifting upward to faculty with higher academic ranks. Castellan found that department chairs attributed

The authors would like to express their thanks to Karen Flemming for her help with data coding and analysis. Correspondence should be sent to Peter A. Hornby, Department of Psychology, State University of New York College, Plattsburgh, NY 12901. lack of use of computers to inadequacy of faculty training, whereas faculty tended to see it as due to lack of time and felt that software was the most important factor contributing to increased use. More recent surveys (Anderson \& Hornby, 1990), while answering questions about the ways in which computers are being used by psychology departments to support instruction, do not provide any information about individual or institutional characteristics associated with such use.

To answer the types of questions mentioned above, it is necessary to obtain data from a large number of individual faculty members who vary in the extent of their instructional use of computers in psychology and who teach at a variety of different types of institutions. The present paper reports the results of a national survey designed to meet these criteria. The following questions are addressed: (1) In what ways and to what extent are computer-skilled psychologists currently using computers in their instruction? (2) What institutional characteristics differentiate among levels of users? (3) What are the characteristics of institutions that appear to promote or inhibit instructional use of computers?

\section{Method}

The questions included in the survey were based in part on earlier surveys of computer use, as well as the authors' judgments regarding individual and institutional characteristics that might be related to the use of computers in instruction. The resulting 25 -question survey was mailed to all individuals believed to have academic affiliations with an American college or university who were included on the mailing lists of the Society for Computers in Psychology (SCiP) or the COMPsych Software Information Service. This resulted in a mailing list of 763 individuals. This sample was selected because these individuals were known to be interested in the use of computers in 
psychology but would most likely vary in the extent and manner of their use to support instruction.

The survey was administered during the spring of 1993. A postage-paid return envelope was enclosed, and individuals responded anonymously. Responses were encouraged, regardless of the extent of the individual's use of microcomputers in instruction.

\section{Survey Results}

A total of $292(38 \%)$ of the surveys were returned. Since the survey was distributed to a nonrandom sample of psychology faculty, and the yield no doubt presents a further bias in the sample, it is important to consider the specific characteristics of the sample. Therefore, a general description of the institutional and individual characteristics of the respondents is reported before addressing questions about the types and extent of instructional computer use.

\section{Institutional Characteristics}

The primary characteristics of the respondents' institutions are reported in Table 1. There were more public than private institutions represented, and a slight tendency toward urban rather than rural settings. Most of the schools offer at least limited graduate education, with many having a strong graduate orientation. The level of psychology degrees offered varies considerably. Schools with both strong teaching and strong research orientations are represented. The size of the student body reflects a considerable range. Finally, most schools are connected to electronic mail.

\section{Individual Characteristics}

The primary characteristics of the individual respondents are presented in Table 2. Most respondents hold a $\mathrm{PhD}$ and have tenure. Number of years of teaching varies from less than 5 to more than 30 , with a fairly equal dis-

Table 1

Institutional Characteristics of Respondents $(N=292)$

\begin{tabular}{lrr}
\hline & Number & Percentage \\
\hline Affiliation & & \\
$\quad$ Private & 111 & 38.0 \\
Public & 177 & 60.6 \\
Setting & & \\
Urban & 85 & 29.1 \\
$\quad$ Rural & 56 & 19.1 \\
Size & & \\
< 5,000 students & 75 & 25.6 \\
5,000-10,000 students & 74 & 25.3 \\
> 10,000 students & 137 & 46.9 \\
Level & & \\
Primarily undergraduate & 50 & 17.1 \\
Limited graduate programs & 116 & 39.7 \\
Strong graduate programs & 103 & 35.3 \\
Major Emphasis & & \\
Teaching & 193 & 66.1 \\
Research & 131 & 44.9 \\
Psychology Degrees Offered & & \\
BA/BS & 256 & 87.7 \\
MA/MS & 180 & 61.6 \\
PhD & 130 & 44.5 \\
Psy.D. & 16 & 5.5 \\
E-Mail Connected & 241 & 82.5 \\
\hline
\end{tabular}

Table 2

Individual Characteristics of Respondents $(N=292)$

\begin{tabular}{|c|c|c|}
\hline & Number & Percentage \\
\hline \multicolumn{3}{|l|}{ Highest Degree } \\
\hline $\mathrm{BA} / \mathrm{BS}$ & 7 & 2.4 \\
\hline $\mathrm{MA} / \mathrm{MS}$ & 22 & 7.5 \\
\hline $\mathrm{PhD}$ & 261 & 89.4 \\
\hline \multicolumn{3}{|l|}{ Years of Teaching } \\
\hline $0-5$ & 34 & 11.6 \\
\hline $6-10$ & 37 & 12.7 \\
\hline $10-20$ & 89 & 30.5 \\
\hline $20-30$ & 106 & 36.3 \\
\hline$>30$ & 25 & 8.6 \\
\hline \multicolumn{3}{|l|}{ Academic Rank } \\
\hline Lecturer & 19 & 6.5 \\
\hline Assistant professor & 42 & 14.4 \\
\hline Associate professor & 67 & 23.0 \\
\hline Full professor & 157 & 53.8 \\
\hline \multicolumn{3}{|l|}{ Hold Continuing Appointment } \\
\hline Yes & 252 & 86.3 \\
\hline No & 26 & 8.9 \\
\hline \multicolumn{3}{|l|}{ Research Areas } \\
\hline Cognition & 134 & 45.9 \\
\hline Sensation \& perception & 72 & 24.7 \\
\hline Research methods & 55 & 18.8 \\
\hline Human learning & 53 & 18.2 \\
\hline Animal behavior & 38 & 13.0 \\
\hline Other areas & 35 & 12.0 \\
\hline \multicolumn{3}{|l|}{ Teaching Areas } \\
\hline Research methods & 126 & 43.2 \\
\hline Statistics & 123 & 42.1 \\
\hline General & 114 & 39.0 \\
\hline Cognition & 113 & 38.7 \\
\hline Learning & 61 & 20.9 \\
\hline Physiological & 35 & 12.0 \\
\hline Social & 34 & 11.6 \\
\hline History \& systems & 10 & 3.4 \\
\hline Other & 31 & 10.6 \\
\hline
\end{tabular}

tribution throughout the range. Over half are full professors. Twenty percent of the sample are women. In terms of research areas represented, cognition and sensation/ perception are dominant. Research methods, statistics, general psychology, and cognition are the most frequently taught courses. Although there is considerable variation on these characteristics, it can be seen that this sample is not representative of the full range of psychology research and teaching fields. Finally, only 4 individuals reported that their school had a specific mandate to use computers in instruction.

\section{Institutional Support for Instructional Computing}

The data suggest a high level of support for instructional computing. It was reported that $58 \%$ of the schools have a college-wide support facility and $25 \%$ have such a facility within the department. It is noteworthy, however, that a total of 73 schools $(25 \%)$ have no specific facility, or the respondent was not aware of one. Nevertheless, most faculty (92\%) report that they think their college would support their efforts to use computers in their instruction, and many commented that they have already received such support. The level of support provided suggests that the use of computers in instruction is valued by most institutions. However, when asked whether they think such use would be positively evalu- 
ated for tenure and promotion at their institution, $34 \%$ said "no" and only $20 \%$ said "yes," with the remainder being uncertain.

\section{Individual Use of Computers}

The individuals sampled reported extensive use of computers. Compared with others in their departments, $85 \%$ rate themselves as average or greater in the use of computers for word processing, experiment generation, data analysis, e-mail, record keeping, and "other" uses. Totaling up the number of hours of computer use, the average individual reported more than 40 hours per week. Ninetyone percent have a computer in their office, $92 \%$ have one in their home, and $68 \%$ have one in their lab. Many individuals reported knowing BASIC (70\%), followed by FORTRAN, Pascal, and "other" (about $40 \%$ each). Overall, the extensive amount of computer use, computer access, and knowledge of programming languages is consistent with what would be expected for SCiP and COMPsych members.

\section{Instructional Use of Computers}

Many of the individuals responding to the survey actively use computers in their instruction. Eighty-nine percent reported that they use computers for instruction at least as much as or more than others in their department. In addition, $69 \%$ indicated that they consider themselves to be dedicated users of instructional computing. On the other hand, $66 \%$ indicated that they use the computer for instruction 3 hours or less per week. Approximately $20 \%$ of the sample indicated that they are not using computers at all in their instruction; however, about half of these individuals reported that they were interested or could perhaps be persuaded. Thus, although it is clear that the present sample represents psychologists who are heavily invested in the overall use of computers, they are far from equally involved in their use for instruction.

The survey asked individuals to report their primary teaching responsibilities, as well as to indicate in which courses they were using computers for instruction. From this information, it is possible to determine the relative amount of computer use as a function of course area. Table 3 shows the percentage of individuals who use computerized instruction in their courses in relation to the total number of respondents who teach those courses. Although the relatively small $N$ for some courses suggests caution in generalizing from these findings, the data suggest that computerized instruction is perhaps being used more extensively in some of the more applied areas (e.g., abnormal and deviant testing) than previous survey results have suggested. In addition, general psychology, slightly below the average in our data, has previously been reported as being in the top three courses in terms of computer use (Anderson \& Hornby, 1990; Carpenter, 1986; Castellan, 1982; Couch \& Stoloff, 1989). This finding may be due to changes that have occurred in recent years, the characteristics of the present sample, or the fact that the present data reflect the input of individuals who are actually teaching the course rather than the judgment of a single member of the department. Overall, however, what
Table 3

Use of Computerized Instruction as a Function of Course

\begin{tabular}{lrcc}
\hline & Total & Using Computers & Percentage \\
\hline Abnormal \& deviant & 6 & 6 & 100.0 \\
Research methods & 126 & 117 & 92.9 \\
Sensation/perception & 55 & 47 & 85.5 \\
Statistics & 123 & 105 & 85.4 \\
Testing & 15 & 12 & 80.0 \\
Cognition & 114 & 85 & 74.6 \\
Learning & 61 & 41 & 67.2 \\
General & 114 & 76 & 66.6 \\
Physiological & 35 & 23 & 65.7 \\
Social & 35 & 20 & 57.1 \\
Industrial/organizational & 12 & 6 & 50.0 \\
Comparative & 15 & 6 & 40.0 \\
Motivation & 6 & 2 & 33.3 \\
Clinical & 9 & 3 & 33.3 \\
Counseling & 9 & 3 & 33.3 \\
History \& systems & 29 & 9 & 31.0 \\
Personality & 12 & 3 & 25.0 \\
Educational & 9 & 2 & 22.2 \\
Developmental & 29 & 6 & 20.7 \\
All courses & 814 & 572 & 70.3 \\
\hline
\end{tabular}

these data suggest is that there is substantial use of computerized instruction across a full range of courses, at least by individuals who are heavily invested in computer use.

\section{Institutional Factors Related to Instructional Computing}

To determine those characteristics of institutions that are most clearly related to the use of instructional computing, cross tabulations were computed for each of the surveyed institutional characteristics in relation to the extent of computerized instruction reported. The findings shown in Table 4 are for the factors that yielded a significant chi-square with $p<.05$. These results suggest that computerized instruction in psychology is more prevalent at undergraduate institutions that have a strong teaching emphasis. Schools with a research emphasis and strong graduate programs, particularly those offering doctoral degrees, show less use of computers for teaching. This finding raises questions concerning the assumption that computerized instruction in psychology has grown out of the heavy use of computers in psychological research. It is also noteworthy that the one difference between public and private institutions revealed by our study is the greater availability of instructional laboratory facilities at the private institutions. Although Castellan (1982) found more instructional computing at smaller campuses, the present study found no clear relationship with the size of the student body.

\section{Individual Factors Related to Instructional Computing}

Individual factors were also related to instructional use of computers through cross-tabulation. Again, a chisquare value with a significance level of $p<.05$ was employed. In partial agreement with Castellan (1982), a positive relationship between academic rank and amount of computer use (for testing) was found. Instructional computing is also positively associated with years of teach- 
Table 4

Level of Instructional Computing in Relation to Institutional Factors

\begin{tabular}{lcccc}
\hline \multicolumn{1}{c}{$\begin{array}{c}\text { Institutional } \\
\text { Factor }\end{array}$} & $\begin{array}{c}\text { Overall } \\
\text { Use }\end{array}$ & $\begin{array}{c}\text { Number of } \\
\text { Courses }\end{array}$ & $\begin{array}{c}\text { Instructional } \\
\text { Laboratories }\end{array}$ & Classroom \\
\hline Public school & $*$ & $*$ & Low & $*$ \\
Private school & $*$ & $*$ & High & $*$ \\
Strong graduate programs & Low & Low & Low & Low \\
Undergraduate only & High & High & High & High \\
Master's degree offered & Low & Low & $*$ & Low \\
Doctoral degree offered & Low & Low & Low & Low \\
Research emphasis & Low & $*$ & Low & $*$ \\
Teaching emphasis & High & High & High & High \\
Connection to e-mail & Low & $*$ & $*$ & $*$ \\
\hline
\end{tabular}

*No significant relationship found.

ing. It was found that individuals whose highest degree is at the master's level report engaging in more instructional computing than those who hold a PhD. Knowledge of FORTRAN is also positively related to instructional computing, which may be attributable to the influence of years of teaching, with older faculty more likely to know that language. Having a computer in the office is positively associated with instructional use, but having a computer in the laboratory is negatively associated.

The relationships between instructional use of computers and individuals' stated preferences for methods of instruction also reveal some clear tendencies. Basically, high use of computerized instruction is associated with a preference for the use of classroom demonstrations, laboratory activities, and films. Those who express a preference for lecturing and discussion as their primary teaching mode are less likely than others to be heavily involved in computerized instruction. Of those who are not currently using computerized instruction, individuals who report a strong preference for the use of films were more likely than others to indicate that they could perhaps be persuaded to use computers for instruction. The only factor that was found to relate to whether or not the individual has tenure is the extent to which computers are being used for testing. Nontenured faculty are less likely to use computers in this manner.

\section{Increasing Computer Use}

The final question in the survey asked individuals to indicate which of several factors would encourage them to increase their use of instructional computing. These data are presented in Table 5. Over half of the respondents identified release time and better software as important factors. Evidence of instructional effectiveness and positive evaluation for tenure and promotions appear to be relatively less important. Several respondents noted a desire for more hardware and better facilities, although this item was not specifically included in the question.

What seems particularly interesting, however, is the relationship between the importance of the factors listed in Table 5 and a number of institutional and individual characteristics. Again, using chi-square with $p<.05$, several interesting relationships were found. Identification of release time as an important factor was highest for assistant professors and for those who reported a high level of awareness of available software. The desire for better software was positively associated with number of years of teaching and the perception that such efforts would be positively evaluated for tenure and promotion. The importance of a support center for help with implementation was associated with less knowledge of programming languages. One surprising finding is that those who indicated that their campus did not presently have a support center were no more likely to specify this as an important factor than were those who already have such a center. As might be expected, the importance of counting toward tenure and promotion was related to fewer years of teaching and lower rank, but, surprisingly, not related to tenure itself. Those that would be most influenced by evidence of instructional effectiveness are individuals who are currently not using computers in instruction, but report that they could perhaps be persuaded. A college-wide mandate would appear to have little influence on dedicated users, but would have considerable impact on occasional users and those who are interested or could perhaps be persuaded.

\section{Conclusions}

The results of this survey provide a general picture of the use of computerized instruction in psychology. In addition, a number of factors have been identified as being associated with level of use and potential for increased use. Using these data, it is possible to profile both highand low-level users. Characteristics of an individual least likely to be involved include: (1) teaches personality, developmental, or educational courses, (2) has a $\mathrm{PhD}$, (3) uses lectures and discussion, (4) has been teaching for

\section{Table 5}

Factors That Would Increase Use of Computers in Instruction

\begin{tabular}{lcc}
\multicolumn{1}{c}{ Factor } & Number & Percentage \\
\hline Release time for development & 176 & 60.3 \\
Better software & 162 & 55.5 \\
Support center & 134 & 45.9 \\
$\quad$ (to help with implementation) & & \\
Support center & 120 & 41.1 \\
$\quad$ (to help with software development) & & \\
Evidence of effectiveness & 75 & 25.7 \\
Counting for tenure \& promotion & 73 & 25.0 \\
College mandate & 40 & 13.7 \\
Nothing & 1 & $<1.0$ \\
\hline
\end{tabular}


a short period of time, (5) has a computer in the laboratory, (6) does not know FORTRAN, and (7) teaches at a graduate institution that (8) has a strong research emphasis and (9) places less emphasis on teaching. The most likely user is someone who: (1) teaches statistics, research methods, or in a general experimental area, (2) holds an MA or MS degree, (3) reports high use of films, demonstrations, and laboratory activities, (4) has been teaching for a considerable length of time, (5) has a computer in his/her office, (6) knows FORTRAN, and (7) teaches at an undergraduate institution that (8) has a strong teaching emphasis and (9) less emphasis on research.

Although the type of factors identified above have been found to be related to level and type of use, it should be kept in mind that there is a relatively high level of overall use of computers among the individuals surveyed. Even within this sample, however, there are both institutional and individual characteristics that clearly differentiate among levels and types of instructional use. In addition, although several factors have been identified that could lead to increased instructional use of computers, the specific impact of these factors will be determined to a large extent by the specific characteristics of the individual and the institution. Taken together, these findings suggest that the development of plans to increase the use of computerized instruction will have to give careful consideration to the characteristics of the individuals and the institutions involved.

\section{REFERENCES}

Anderson, M. D., HornBy, P. A. (1989). COMPsych: A description and progress report. Behavior Research Methods, Instruments, \& Computers, 21, 243-245.

ANDERSON, M. D., \& Hornby, P. A. (1990). Computer use in psychology instruction. Behavior Research Methods, Instruments, \& Computers, 22, 194-199.

Carpenter, D. L. (1986). A survey of microcomputer use in small psychology departments. Behavior Research Methods, Instruments, \& Computers, 18, 155-156.

Castellan, N. J., JR. (1982). Computers in psychology: A survey of instructional applications. Behavior Research Methods, Instruments, \& Computers, 16, 145-147.

Couch, J. V., \& Stoloff, M. L. (1989). A national survey of microcomputer use by academic psychologists. Teaching of Psychology, 16, 145-147.

Stoloff, M. L., \& Couch, J. V. (1992). Computer use in psychology: A directory of software (3rd ed.). Hyattsville, MD: American Psychological Association. 